\title{
Maturation of Jejunum and Ileum in Rats
}

\author{
WATER AND ELECTROLYTE TRANSPORT DURING IN VIVO PERFUSION \\ OF HYPERTONIC SOLUTIONS
}

\author{
M. K. Younoszai, R. S. Sapario, and M. Laughlin, Gastroenterology Research \\ Laboratory, Department of Pediatrics, College of Medicine, University of Iowa, \\ Iowa City, Iowa 52242
}

\begin{abstract}
A B S T R A C T During osmotic diarrhea, loss of water and electrolytes appears to be greater in infants than in adults. In 2-, 3-, and 7-wk-old rats, we studied net transport of $\mathrm{H}_{2} \mathrm{O}, \mathrm{Na}$, and $\mathrm{Cl}$, during in vivo perfusion of segments of the jejunum and ileum, from solutions with osmolalities of $300,375,500$, or $700 \mathrm{mosmol} / \mathrm{kg}$. In the jejunal segments, from the hypertonic solutions net transport of $\mathrm{H}_{2} \mathrm{O}, \mathrm{Na}$, and $\mathrm{Cl}$ was into the lumen and greater in the 2- than 7 -wk-old rats. In the ileal segments, transport of water was into the lumen, transport of Na was minimal and variable, whereas transport of $\mathrm{Cl}$ was usually out of the lumen. In 3-wk-old rats, transport rates were intermediate between those in 2 - and 7-wk-old rats. The calculated filtration coefficient (microliters of $\mathrm{H}_{2} \mathrm{O}$ transported per hour per unit osmolality gradient-lumen-serum-per gram dry weight) of water suggested that the resistance to water flow did not increase with rise in luminal hypertonicity in the jejunum of the 2- and 3-wk-old rats, whereas in jejunum of the 7-wk-old rats and in ileum of rats in all three ages, the resistance to water flow increased with the rise in luminal osmolality. The differences in the transport rates and the resistance to water flow, between segments of the 2-, 3-, and 7-wk-old rats, suggested a maturational phenomenon that appears to continue beyond the $3 \mathrm{rd}$ wk of life and could have been due to differences in some physical property of the mucosal membrane.
\end{abstract}

\section{INTRODUCTION}

Infant rats seem to accumulate excessive fluid in the intestine in response to hypertonicity of the luminal contents. Increasing the osmolality of diets fed to infant rats has been associated with increased volume of fluid in the intestinal lumen, hemoconcentration, and

Received for publication 7 October 1977 and in revised form 3 April 1978. serum hyperosmolality (1). These changes were presumably due to increased transport of fluid and electrolytes into and/or decreased transport out of the lumen of the small intestine. During episodes of osmotic diarrhea, as occurs in lactose intolerance secondary to intestinal mucosal injury, human infants appear to be more prone than adults to develop dehydration. This seems to point to a quantitative difference in transport of fluid and electrolytes between the intestine of infants and adults, predisposing the infant to relatively larger losses of fluid from the gastrointestinal tract.

We conducted the present in vivo studies to evaluate the response of the small intestine to luminal hypertonicity in infant (2- and 3-wk-old) and adolescent (7-wk-old) rats. In the 2- and 3-wk-old rats, we also determined the absorption of phenol red used as nonabsorbable marker for water transport and of mannitol used as the impermeant nonelectrolyte solute.

\section{METHODS}

Transport of water and electrolytes was compared in segments of the jejunum and ileum in 2- (14- to 15-day-old), 3- (21- to 22-day-old), and 7-(49-day-old) wk-old male albino rats. These rats were obtained from pregnant rats purchased from Biolab Corp. (St. Paul, Minn.). On the 2 nd day after delivery, newborn pups were randomized among mother rats and litter size maintained at seven to nine pups until the time of study. The experimental procedures used were similar to those described previously $(2,3)$. At the time of study, rats were anesthetized with a solution containing a mixture of ethylurea (K \& K Laboratories Inc., Plainview, N. Y.) and pentobarbital sodium (6:1). 5- to 10 -cm long segments of the jejunum (just distal to the ligament of Treitz) and ileum (just proximal to the ileocecal junction) were rinsed with $10 \mathrm{ml}$ of an isotonic sodium chloride solution, flushed with $50 \mathrm{ml}$ of air, and cannulated. The cannulated segments were inserted back into the abdominal cavity and perfused in situ at a rate of 0.2 $\mathrm{ml} / \mathrm{min}$, with a solution containing, per liter: $145 \mathrm{mmol}$ sodium chloride, $20 \mathrm{mg}$ phenol red, and mannitol (Fisher Scientific Co., Pittsburgh, Pa. ) in quantities sufficient to achieve osmolalities of 375,500 , and $700 \mathrm{mosmol} / \mathrm{kg}$. In an initial study 
of rats at the same age periods, $15-$ to $20-\mathrm{cm}$ long segments of the jejunum and ileum were perfused with the above solution with enough mannitol to achieve osmolalities of 295-305 mosmol $/ \mathrm{kg}$. This solution was slightly hypotonic compared with rat serum osmolality of 305-309 mosmol/kg under normal conditions. For study of the effect of each solution with different osmolality, groups of five to seven rats at each age were used (four groups at each age period). During the perfusion period, the rats' peritoneal temperature was monitored and maintained at $36^{\circ}-37^{\circ} \mathrm{C}$. The solution perfused through the cannulated segments over the first $60 \mathrm{~min}$ of perfusion was discarded, whereas that over the next $60 \mathrm{~min}$ was collected in three consecutive 20 -min periods. The osmolality and concentrations of sodium, chloride, and phenol red were determined in the initial perfusion solutions and in each of the collected solutions (perfusates). After the perfusion period, blood was obtained from the aorta of rats perfused with the hypertonic solutions. The perfused jejunal and ileal segments were stripped from the mesentery and their length measured. The wet weight of the segments was determined after gently pressing out the luminal contents with the forefingers. The segments were then dried in a vacuum oven at $90-95^{\circ} \mathrm{C}$ for $24 \mathrm{~h}$ and its dry weight determined.

Immediately after the perfusion period, osmolality of the serum and solutions (except in the initial study) was determined by freezing point with an osmometer (Advanced Osmometer, model 3W, Advanced Instruments, Inc., Needham Heights, Mass.); sodium was measured with a flame photometer (model 143, Instrumentation Laboratory, Inc., Lexington, Mass.); chloride was measured with a chloridometer (model CMT 10 Chloride Titrator, Radiometer Co., Copenhagen, Denmark); and phenol red as described by Schedl and Clifton (4).

Net water transport was determined from change in concentration of phenol red as follows: Net water transport, milliliter/20 $\min =V_{i}\left(1-P R_{i} / P R_{f}\right)$, where $V$ depicts volume of fluid perfused milliliter $/ 20 \mathrm{~min}$, and $\mathrm{PR}$ the concentration of phenol red in micrograms/milliliter, in the perfusion fluids. The subscripts $i$ and $f$ refer to initial and final values in the perfusion solutions before perfusion $(i)$, and in the perfusates collected $(f)$.

Net solute transport was calculated from change in volume and osmolality of the solutions perfused.

Net solute transport, micromoles $/ 20 \mathrm{~min}=\mathrm{V}_{i}\left(\mathrm{O}_{i}-\mathrm{O}_{f} \mathrm{PR}_{i}\right)$ $\mathrm{PR}_{f}$ ), where $O$ is osmolality in microosmoles per gram of perfusion fluid; the other symbols have the same meaning as above.

Net transport of sodium and chloride were calculated similarly. Concentration (C, micromoles/milliliter) of sodium or chloride replaced the osmolality of solutions $(\mathrm{O})$ in the above formula: Net transport, micromoles $/ 20 \min =\mathrm{V}_{i}\left(\mathrm{C}_{i}-\mathrm{C}_{f} \mathrm{PR}_{i} /\right.$ $\mathrm{PR}_{f}$ ).

Net transport out of the lumen will be referred to as outflux or absorption and that into the lumen as influx or secretion.

During the 60-min collection period, steady-state conditions had been achieved because net transport of water, total solute, sodium and chloride, during each of the three 20-min collection periods, did not vary from each other by more than $15 \%$. The amounts of water and of electrolyte transported during these three periods were added to obtain amount transported in $1 \mathrm{~h}$. To be able to compare transport rates of water and electrolytes in the segments of the rats at the different age groups, the amounts transported were normalized for the marked differences in size (weight) of the perfused segments (Table I).

Because absorption of significant amounts of phenol red and mannitol during perfusion of the segments would have affected the calculated rates of water and electrolyte transport, we determined the absorption of phenol red and mannitol in six 2-wk-old and three 3-wk-old rats. Absorption of phenol red and mannitol in the small intestine of the adult rat has been studied previously (5). For these experiments, 10- to $15-\mathrm{cm}$ segments of the jejunum and ileum were prepared as described above. The perfused solutions contained, per liter: $50 \mathrm{mg}$ phenol red, $145 \mathrm{mmol}$ sodium chloride, $20 \mathrm{mmol}$ mannitol, and $1 \times 10^{5} \mathrm{dpm} / \mathrm{ml}$ of $\left[{ }^{14} \mathrm{C}\right]$ mannitol (New England $\mathrm{Nu}-$ clear, Boston, Mass., $5 \mathrm{mCi} / \mathrm{mg}$ ). The rate of perfusion was $0.3 \mathrm{ml} / \mathrm{min}$. The method used for determining phenol red absorption and recovery rates was similar to that used in the adult rats (5).

Statistical analysis. The unpaired $t$ test was used to compare mean values between corresponding segments of rats at the three age periods, and the paired $t$ test to compare mean values between the segments in each group of rats. A value of $P<0.05$ was taken as indicating a statistically significant difference between the corresponding mean values (6).

\section{RESULTS}

Table I shows body weight and the measurements of the perfused intestinal segments for the rats studied. In the groups of rats perfused with the hypertonic solutions, because body weight and measurements of the perfused intestinal segments were similar in rats of the same age, corresponding values were combined and the means presented in Table I. In the groups of rats perfused with the slightly hypotonic solutions, although length and weight of the segments were almost twice as great, wet weight/centimeter ratios were similar to corresponding values of the rats perfused with the hypertonic solutions. Intestinal segment weight and weight/centimeter ratios were several times greater in the 7 -wk-old than in the younger rats. Water content of both the jejunal and ileal segments decreased significantly $(P<0.01)$ to about $77 \%$ when the osmolality of the solutions perfused increased over $375 \mathrm{mosmol} / \mathrm{kg}$, except in the 2 -wk-old rats, where the water content of the jejunal segment was $75.7 \%$ even when the perfusion solutions osmolality was $375 \mathrm{mosmol} / \mathrm{kg}$. This value was significantly lower than the corresponding ileal value $(79.6 \%), P<0.01$, and also significantly lower as compared with water content $(80-81 \%)$ of the jejunal segment of the 3-and 7-wk-old rats perfused with the solutions of the same osmolality $(P<0.01)$. Although size of the segments perfused was markedly different in the rats at different ages, total amount of water transported into the lumen of the segments as $1 / \mathrm{h}$ (Table I), in response to perfusion of the hypertonic solutions, was not very different in corresponding segments of the 2-, 3-, and 7-wk-old rats.

Table I also shows the total amount of phenol red and mannitol recovered as a percent of the total amount perfused in the segments of the 2- and 3-wk-old rats. In the 2-wk-old rats, $2 \%$ of phenol red and of mannitol could not be recovered from the jejunal segments, and about $4 \%$ of both markers could not be recovered from the ileal segments. Recoveries of phenol red and man- 
TABLE I

Body Weight, Measurements* of the Perfused Intestinal Segments, Net Water Transport, and Recovery of Phenol Red and Mannitol in the Rats Studied $\$$

\begin{tabular}{|c|c|c|c|c|c|c|}
\hline \multirow{3}{*}{$\begin{array}{r}\text { Body wt, } g \ldots \ldots \ldots \ldots \ldots \ldots \ldots \ldots \ldots \\
\text { Intestinal segment perfused }\end{array}$} & \multicolumn{6}{|c|}{ Age } \\
\hline & \multicolumn{2}{|c|}{$\begin{array}{l}2 \mathrm{wk} \\
29 \pm 1\end{array}$} & \multicolumn{2}{|c|}{$\begin{array}{l}3 \mathrm{wk} \\
50 \pm 3\end{array}$} & \multicolumn{2}{|c|}{$\begin{array}{c}7 \mathrm{wk} \\
208 \pm 6\end{array}$} \\
\hline & Jejunum & Ileum & Jejunum & Ileum & Jejunum & Ileum \\
\hline Length, $\mathrm{cm}$ & $8.1 \pm 0.4$ & $9.3 \pm 0.6$ & $6.9 \pm 0.5$ & $7.3 \pm 0.4$ & $7.6 \pm 0.3$ & $6.5 \pm 0.4$ \\
\hline Wet wt, $m g$ & $103 \pm 8$ & $127 \pm 10$ & $177 \pm 12$ & $148 \pm 11$ & $554 \pm 22$ & $431 \pm 28$ \\
\hline Wet wt, $\mathrm{mg} / \mathrm{cm}$ & $12.8 \pm 0.8$ & $13.6 \pm 0.7$ & $25.5 \pm 0.8$ & $20.3 \pm 0.7$ & $71.6 \pm 1.2$ & $66.3 \pm 1.4$ \\
\hline \multicolumn{7}{|c|}{$\begin{array}{l}\text { Net water transport, } \mu l / h \S \\
\text { Osmolality of perfusion solution, } \\
\text { mosmol/kg }\end{array}$} \\
\hline $295-305$ & $58 \pm 79$ & $88 \pm 57$ & $-203 \pm 56$ & $-228 \pm 111$ & $-340 \pm 130$ & $-474 \pm 146$ \\
\hline 375 & $257 \pm 33$ & $219 \pm 35$ & $248 \pm 41$ & $144 \pm 47$ & $177 \pm 48$ & $565 \pm 63$ \\
\hline 500 & $605 \pm 48$ & $358 \pm 60$ & $811 \pm 98$ & $405 \pm 50$ & $759 \pm 110$ & $369 \pm 53$ \\
\hline 700 & $1,010 \pm 57$ & $461 \pm 96$ & $834 \pm 121$ & $435 \pm 48$ & $994 \pm 141$ & $609 \pm 86$ \\
\hline \multicolumn{7}{|l|}{$\begin{array}{l}\text { Water content, } m g / 100 \mathrm{mg} \S \\
\text { Osmolality of perfusion solution, } \\
\text { mosmol/kg }\end{array}$} \\
\hline $295-305$ & $79.7 \pm 0.5$ & $81.5 \pm 0.4$ & $79.9 \pm 0.3$ & $81.1 \pm 0.4$ & $80.5 \pm 0.3$ & $83.1 \pm 0.3$ \\
\hline 375 & $75.7 \pm 0.9^{\prime \prime}$ & $79.6 \pm 0.9 \pi$ & $80.4 \pm 0.5$ & $80.8 \pm 1.1^{9}$ & $81.6 \pm 0.7 \pi$ & $80.8 \pm 0.4^{\pi}$ \\
\hline 500 & $75.6 \pm 0.6$ & $77.1 \pm 1.0$ & $76.7 \pm 0.5$ & $76.8 \pm 0.8$ & $77.2 \pm 0.5$ & $76.6 \pm 0.4$ \\
\hline 700 & $76.6 \pm 0.7$ & $76.9 \pm 0.6$ & $77.1 \pm 0.4$ & $77.8 \pm 0.4$ & $77.5 \pm 0.7$ & $77.7 \pm 0.6$ \\
\hline $\begin{array}{l}\text { Recovery of phenol red as total } \\
\text { amount perfused, percent }\end{array}$ & $97.9 \pm 0.7$ & $96.2 \pm 0.4$ & $97.6 \pm 0.8$ & $97.9 \pm 0.7$ & $98.2 \pm 1.0 \ddagger \ddagger$ & $97.6 \$ \ddagger$ \\
\hline $\begin{array}{l}\text { Recovery of mannitol as total } \\
\text { amount perfused, percent }\end{array}$ & $97.9 \pm 0.4$ & $96.1 \pm 0.6$ & $98.9 \pm 0.8$ & $98.2 \pm 0.6$ & & \\
\hline
\end{tabular}

Values are mean $\pm \mathrm{SE}$.

* Segment measurements and water content of full-thickness wall were obtained at the end of the 2-h perfusion period.

$\$$ At each age period four separate groups of five to seven rats were studied.

$\S$ Net transport of water into the lumen (secretion) is indicated as positive and net transport out of the lumen (absorption), as negative numbers.

" Mean value in the 2 -wk-old rats is significantly different from corresponding mean values in 3 - and 7 -wk-old rats, $P<0.01$.

T Mean value in segments perfused with solution of $375 \mathrm{mosmol} / \mathrm{kg}$ is significantly different from corresponding mean values in segments perfused with solutions of higher osmolality, $P<0.01$.

** These studies were performed in six 2-wk-old rats and three 3-wk-old rats. Care was taken to collect as much of the perfused solutions as possible. Volume of solutions perfused and recovered were determined from their weight. The method of perfusion, collection of the perfusates, and rinses were similar to those used in adult rats (5).

$\sharp \ddagger$ The values for the adult rats were taken from published data $(5,18)$.

nitol in the 3-wk-old rats were very similar to those in the 2-wk-old rats. The amount not recovered was either absorbed and/or lost from the tubing during the manipulations. Only traces of $\left[{ }^{14} \mathrm{C}\right]$ mannitol could be detected in the mucosal scraping and in the blood of the rats. For comparison, total recoveries of phenol red and mannitol from intestinal segments of adult rats, reported by Miller and Schedl (5), are also shown in Table I.

Because of the differences in the weight/centimeter ratios and the water content of the segments between rats of different ages, net transport rates of water and electrolytes were compared when expressed on the basis of dry weight of the perfused segments and are shown in Figs. 1 and 2. Net transport rates expressed on the basis of wet weight of the perfused segments had the same relationships as those expressed on the basis of dry weight of the segments.

Net water transport. Perfusion with the slightly hypotonic solution was associated with variable water transport, at $2 \mathrm{wk}$ there was influx, whereas at 3 and $7 \mathrm{wk}$ there was outflux. Perfusion with each of the three hypertonic solutions induced influx of water into the segments at all three age periods. In the jejunum (Fig. $1 a)$, rate of water influx increased with the rise in osmolality of the perfusion solution. When osmolality of perfusion solution was over $375 \mathrm{mosmol} / \mathrm{kg}$, rate of water influx was significantly greater in the 2 - than 7 -wk-old rats $(P<0.005)$. In the 3 -wk-old rats, rate of water influx was intermediate between the correspond- 

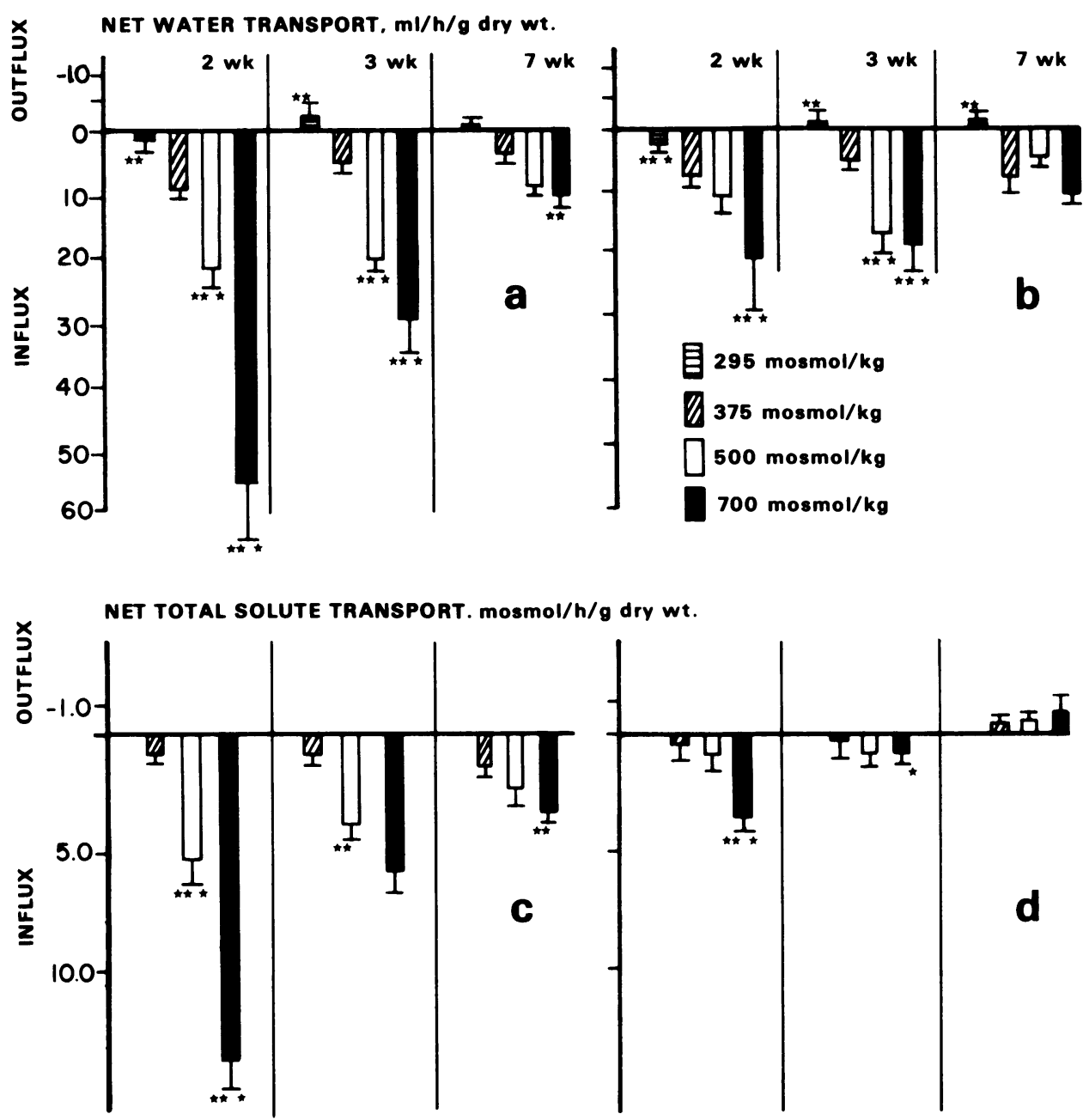

Figure 1 Net transport of water and total solute in segments of the jejunum and ileum of 2-, 3 -, and 7-wk-old rats perfused with solutions containing sodium chloride ( $145 \mathrm{mmol} / \mathrm{liter})$ and mannitol. Influx depicts net transport into (secretion), and outflux, net transport out (absorption) of the lumen of the perfused segments. Transport rates are based on dry weight to normalize for marked differences in size of the segments between rats at the different ages. The height of the bar depicts the mean value and the vertical lines the SE. The single stars show mean values in the 2 - and 3 -wk-old rats that were significantly different from corresponding mean values in the 7 -wk-old rats, $P<0.05-0.001$. The double stars indicate mean values in segments perfused with solution of $295-305,500$, or $700 \mathrm{mosmol} / \mathrm{kg}$ that were significantly different from corresponding mean values in segments perfused with the solution of $375 \mathrm{mosmol} / \mathrm{kg}, P<0.05-$ 0.005 .

ing values of the 2 - and 7 -wk-old rats. In the ileum (Fig. $1 b)$, influx of water in response to perfusion of the hypertonic solutions was not as marked as in the corresponding jejunum. In the 2- and 3-wk-old rats, influx increased significantly when perfusion solution osmolality increased from 375 to $700 \mathrm{mosmol} / \mathrm{kg}(P$ $<0.001)$, whereas in the 7 -wk-old rats there was no significant change in water influx.

Net solute transport. In the jejunum (Fig. 1c), influx of solute increased with the rise in osmolality of the perfusion solution, and rate of solute influx was greater in 2- than 7-wk-old rats. In the ileum (Fig. 1d), there was influx of solute in the 2 -wk-old rats but outflux in the 7-wk-old rats. The transport rates for total solute were significantly different in the jejunal than in the corresponding ileal segments at all three age periods $(P<0.05)$.

Net sodium transport. In the jejunum (Fig. 2a), 

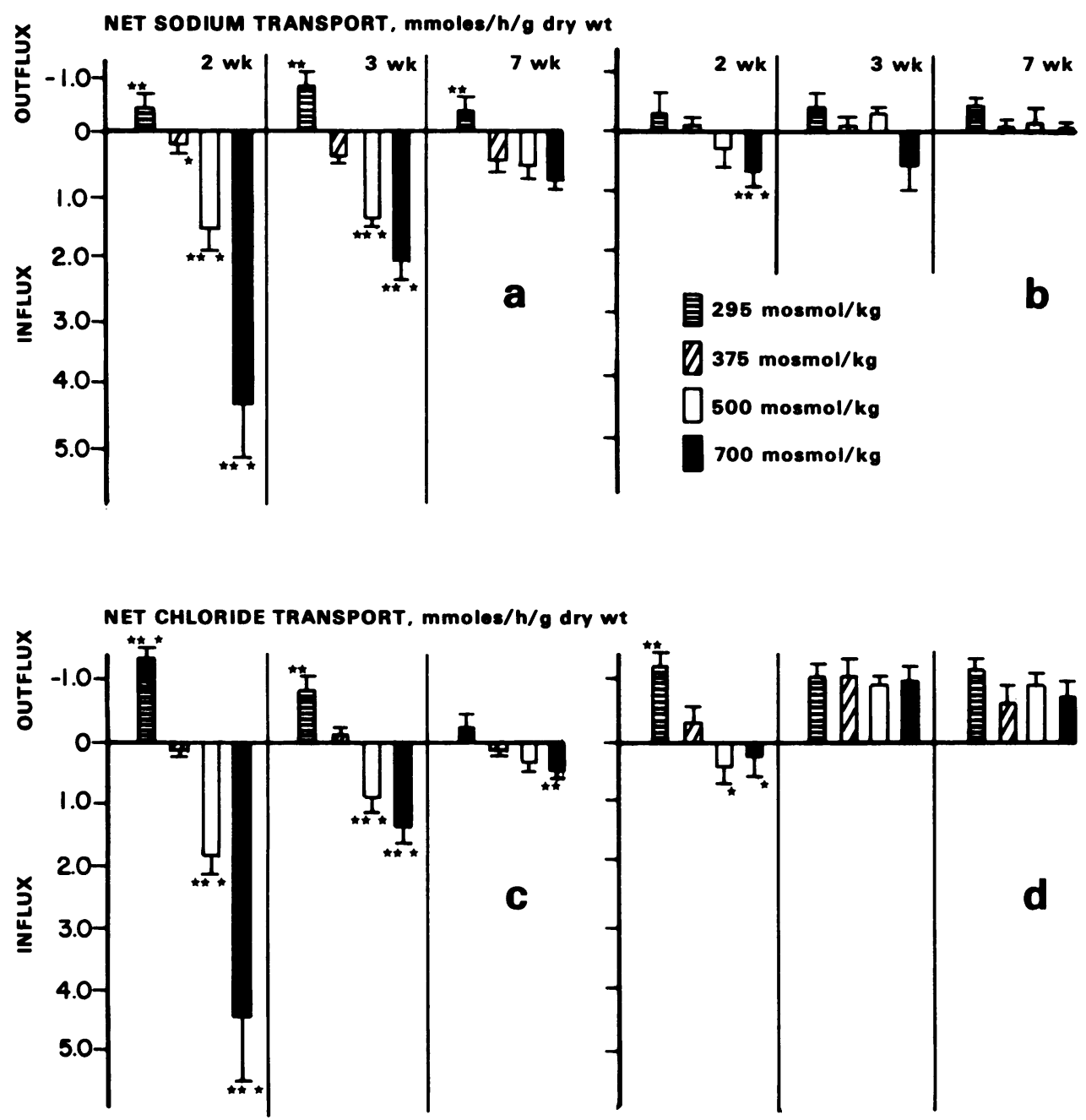

Figure 2 Net transport of sodium and chloride in the perfused jejunum and ileum of the rats studied. Explanations of the perfusion solutions and symbols used are given in the legend of Fig. 1.

perfusion of the slightly hypotonic solution caused outflux, whereas perfusion of each of the three hypertonic solutions induced influx of sodium. Rate of sodium influx was significantly higher in the 7 - than in the 2 -wk-old rats when perfusion solution osmolality was $375 \mathrm{mosmol} / \mathrm{kg}(P<0.05)$. However, when the perfusion solution osmolality was 500 and $700 \mathrm{mosmol} / \mathrm{kg}$, influx rates were severalfold greater in the 2- than in the 7 -wk-old rats $(P<0.05)$. Rates of influx of sodium in jejunal segments of the 3-wk-old rats were intermediate between the corresponding values of the 2and 7-wk-old rats. In contrast to the jejunum, in the ileum (Fig. 2b) sodium transport varied between influx and outflux. When perfusion solution osmolality was $700 \mathrm{mosmol} / \mathrm{kg}$, there was influx of sodium in the 2- and 3-wk-old rats, whereas in 7-wk-old rats there was slight outflux. The mean rates of sodium transport in the ileal segments of the rats at the three age periods were not significantly different from each other.

Net chloride transport. In the jejunum (Fig. 2c), perfusion of the slightly hypotonic solution caused greater outflux of chloride in the 2- than the 7-wk-old rats $(P<0.01)$. Perfusion of solutions with osmolality $>375 \mathrm{mosmol} / \mathrm{kg}$ caused influx of chloride that was significantly greater in 2 - than in 7 -wk-old rats $(P<0.01)$. The corresponding values in the 3-wk-old rats were intermediate between those in the 2 - and the 7-wk-old rats. In the ileum (Fig. $2 d$ ) of the 2-wk-old rats, per- 
fusion with the solutions of 295 and $375 \mathrm{mosmol} / \mathrm{kg}$, induced outflux of chloride; however, perfusion with solutions of 500 and $700 \mathrm{mosmol} / \mathrm{kg}$ was associated with influx of chloride. In the 3-and 7-wk-old rats, the ileum transported chloride out of the lumen, regardless of the osmolality of perfusion solution. Rate of chloride outflux was not significantly different at the three levels of osmolality in the 3- and 7-wk-old rats.

Serum osmolality (milliosmoles/kilogram). At the end of the perfusion period, serum osmolality (shown in Table II) in rats perfused with the hypertonic solutions was significantly $(P<0.01)>306 \pm 1 \mathrm{mosmol} / \mathrm{kg}$ found in rats of similar ages in whom the intestine was not perfused (10 rats) or perfused with isotonic solutions (15 rats) of $295-305 \mathrm{mosmol} / \mathrm{kg}$. With the rise in osmolality of the solutions perfusing the segments, the osmotic gradient between lumen and serum increased. This osmotic pressure gradient between lumen and serum was probably the most important factor causing net transport of water into the lumen of the perfused jejunal and ileal segments.
In Fig. 3 rate of water transport is plotted against the osmotic pressure gradient between lumen and serum, at the end of the perfusion period. In the jejunum (Fig. $3 a$ ) in the 2 -wk-old rats, rate of water influx increased in proportion to the rise in osmotic gradient, and the relation between rate of water influx and osmotic gradient was linear. In the 7 -wk-old rats, the relationship was blunted and nonlinear. In the 3-wk-old rats, the relationship was intermediate between those in the 2 - and 7-wk-old rats. In the ileum (Fig. 3b), the relationship between rate of water transport and osmotic gradient from the hypertonic solutions was blunted and nonlinear, and the increment in water influx, in response to the rise in osmotic gradient, was much lower than in the corresponding jejunum $(P<0.01)$. In the 7 -wk-old rats, there appeared to be no increase in water influx with the rise in the osmotic gradient of over about $40 \mathrm{mosmol} / \mathrm{kg}$.

The permeability of the mucosal membranes to water can be assessed by expressing transport of water on the basis of unit osmotic pressure gradient between

TABLE II

Serum Osmolality and the Calculated Filtration Coefficient of Water in the Perfused Intestinal Segments in the Groups of Rats Studied

\begin{tabular}{|c|c|c|c|c|c|c|}
\hline & \multicolumn{6}{|c|}{ Age } \\
\hline & \multicolumn{2}{|c|}{$2 \mathrm{wk}$} & \multicolumn{2}{|c|}{$3 \mathrm{wk}$} & \multicolumn{2}{|c|}{$7 \mathrm{wk}$} \\
\hline \multicolumn{7}{|l|}{ Serum osmolality, mosmol/kg* } \\
\hline \multicolumn{7}{|l|}{$\begin{array}{l}\text { Osmolality of perfusion solutions, } \\
\text { mosmol/kg }\end{array}$} \\
\hline $295-305+$ & \multicolumn{2}{|c|}{$305 \pm 1$} & \multicolumn{2}{|c|}{$306 \pm 1$} & \multicolumn{2}{|c|}{$306 \pm 1$} \\
\hline 375 & \multicolumn{2}{|c|}{$330 \pm 1$} & \multicolumn{2}{|c|}{$319 \pm 1$} & \multicolumn{2}{|c|}{$323 \pm 1$} \\
\hline 500 & \multicolumn{2}{|c|}{$339 \pm 1$} & \multicolumn{2}{|c|}{$332 \pm 2$} & \multicolumn{2}{|c|}{$344 \pm 2$} \\
\hline 700 & \multicolumn{2}{|c|}{$340 \pm 1$} & \multicolumn{2}{|c|}{$335 \pm 2$} & \multicolumn{2}{|c|}{$344 \pm 2$} \\
\hline \multicolumn{7}{|l|}{ Filtration coefficient of water $\S$} \\
\hline Intestinal segment & Jejunum & Ileum & Jejunum & Ileum & Jejunum & Ileum \\
\hline \multicolumn{7}{|l|}{$\begin{array}{l}\text { Osmolality of perfusion solutions, } \\
\text { mosmol/kg }\end{array}$} \\
\hline $295-305^{\prime \prime}$ & - & - & - & - & - & - \\
\hline 375 & $130 \pm 15$ & $100 \pm 11$ & $75 \pm 10$ & $90 \pm 8$ & $75 \pm 7$ & $90 \pm 5$ \\
\hline 500 & $145 \pm 18$ & $67 \pm 8$ & $108 \pm 9$ & $75 \pm 7$ & $47 \pm 5$ & $29 \pm 5$ \\
\hline 700 & $163 \pm 20$ & $59 \pm 5$ & $80 \pm 12$ & $51 \pm 6$ & $32 \pm 4$ & $25 \pm 4$ \\
\hline
\end{tabular}

Values are mean $\pm \mathrm{SE}$.

* Serum osmolality was measured in blood obtained at the end of the 2 -h perfusion period. Serum osmolality in rats of similar age whose intestines were not perfused (10) was $306 \pm 1 \mathrm{mosmol} / \mathrm{kg}$.

\$ The serum osmolalities indicated are those obtained in rats in other studies, whose jejunal and ileal segments $(15-20 \mathrm{~cm})$ were perfused with solutions of sodium chloride, $145 \mathrm{mmol} / \mathrm{liter}$, and mannitol with osmolalities of 295-305 mosmol/kg.

$\S$ Filtration coefficient of water is defined as net transport rate (microliter per hour per gram dry wt) per unit osmolality gradient between lumen and serum. The values for luminal osmolality used in the calculations were the final perfusion fluid osmolality. The filtration coefficient is an index of the permeability of the mucosal membrane to water. Decreasing values show increasing resistance to water movement across the mucosal membrane. Per unit osmolality gradient, resistance to water influx (normalized for differences in intestinal segment size), increased with the rise in luminal hyperosmolality except for the jejunal segments of the 2- and 3-wk old rats.

"The filtration coefficient for these segments could not be calculated because final perfusion fluid osmolality was not obtained for these groups of rats. 


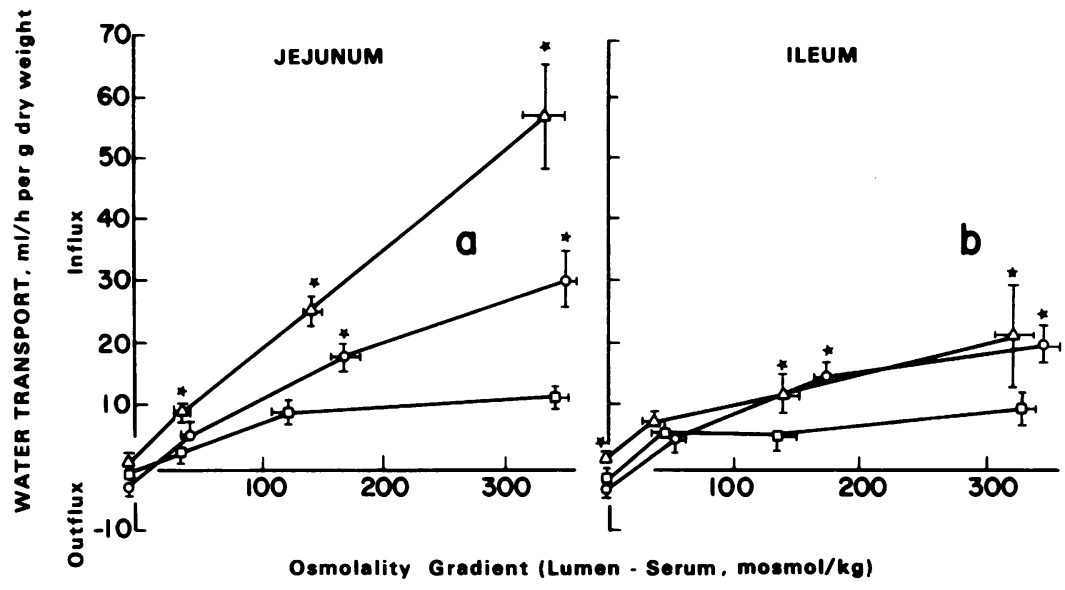

FIGURE 3 The relationship between net water transport and osmolality gradient between lumen and serum in segments of the jejunum and ileum of $(x-x) 2-,(O-O) 3-$, and $(\square-\square)$ 7 -wk-old rats. The segments were perfused with solutions containing sodium chloride ( $145 \mathrm{mmol} /$ liter) and mannitol with osmolalities of $300,375,500$, or $700 \mathrm{mosmol} / \mathrm{kg}$. The symbols indicate mean values, and vertical lines the SE. The stars depict the mean values in the 2- and 3-wk-old rats that were significantly different from corresponding mean values in the 7 -wk-old rats, $P<0.05-<0.005$. The osmolality gradients shown in the figure represent values obtained at the end of the perfusion period. The same relationships between net water transport and osmolality gradient were obtained when the osmolality gradient was calculated by the geometric or logarithmic mean values. The geometric and arithmetic mean values for the serum were estimated (assuming normal initial serum osmolality).

lumen and serum. This has been termed the "filtration coefficient" of water (7). Because of the marked difference in size of the segments between rats at the three age periods, transport of water should ideally be corrected for surface area of the mucosa. Unfortunately, surface area is difficult if not impossible to measure. We have used dry weight of the segments perfused to normalize for the differences in size and surface area between segments of the rats at the three age periods. The calculated values for the filtration coefficient are shown in Table II. In the jejunal segments, from the slightly hypotonic solution, water movement was against the osmotic gradient in the 2 -wk-old rats; in the older rats the estimated filtration coefficient was high and appeared to be greater in the 3- than in the 7-wk-old rats. From the hypertonic solutions, the filtration coefficient in the 2 -wk-old rats increased with the rise in the osmolality of the perfusion solution. In the 3-wk-old rats, there was no consistent change. In the 7-wk-old rats, the filtration coefficient dropped to one-half with the rise in perfusion osmolality from 375 to $700 \mathrm{mosmol} / \mathrm{kg}$. In the ileal segments at all three age periods, the filtration coefficient fell to over one-half with the rise in luminal osmolality from 375 to $700 \mathrm{mosmol} / \mathrm{kg}$.

\section{DISCUSSION}

Water transport across the intestinal epithelium is affected by the osmolality of the luminal contents. As expected, in the perfused intestinal segments net water transport was in the direction of the osmotic gradient between lumen and serum, except in the segments of the suckling rats perfused with the slightly hypotonic solution (Fig. 2), where water transport was against the relatively small osmotic gradient. Body water content (8) and extracellular volume appear to be greater in suckling than in older rats. Because extracellular volume expansion induces distension of the intercellular spaces in the intestinal epithelium and secretion of water into the lumen (9), it may be assumed that the expected relative state of extracellular volume expansion in suckling rather than in older rats induced water flow into the lumen of the segments of the suckling rats. Inasmuch as in this and other published $(2,3)$ and unpublished studies, water content of the fullthickness intestinal wall, or of the mucosal scrapings and underlying tissues of segments perfused with slightly hypotonic solutions, was equal to or lower in suckling (mucosal scrapings, 79\%; underlying tissues, $76 \%$ ) than in older (mucosal scrapings, $82 \%$; underlying tissues, $78 \%$ ) rats, it seemed unlikely that tissue water content played an important role in transport of water in the segments perfused with the slightly hypotonic solution.

In "leaky" epithelia, such as that of the small intestine, the proximal kidney tubule, and the gall bladder, where the electric conductance across the intercellular spaces forms around $80-96 \%$ of the total transepithelial conductance (10-13), most of the passive ion transport across the epithelium occurs through the intercellular spaces $(10,14-19)$. Water flows into these 
spaces in response to a local osmotic gradient produced by active or passive solute transport into these spaces $(10,14-19)$. From the mucosal medium, flow of water into the intercellular spaces can be directly through the tight junctions (18) and/or through the cell membranes, and is associated with dilatation of the spaces (20-22). The cross-sectional area of these spaces increases progressively with increasing rates of flow. This increase in area does not influence hydraulic permeability (23). On the other hand, when water flows from the mucosa into the lumen in response to luminal hypertonicity, the intercellular spaces decrease in size and collapse (20-23). This diminution in size is associated with an increase in transepithelial electric resistance $(21,23)$, a decrease in the permeability of the tissue to hydrophilic molecules $(21,23)$, and a decrease in hydraulic conductivity for osmotic flow from isotonic serosal to hypertonic mucosal media (21). These findings are consistent with the concept that in "leaky" epithelium with increasing luminal hypertonicity, volume of flow toward the lumen becomes a function of the area of the intercellular spaces. As the intercellular spaces collapse, the volume of flow will be nonlinearly related to the osmotic gradient $(21,23)$, and has been described in the rabbit gall bladder by Diamond (24) as "nonlinear osmosis."

In the present study, the nonlinear relationships between the osmotic gradient (lumen-serum) and rates of water influx into the jejunal segments of the 3-and 7-wk-old rats and in the ileal segments of rats at all three age periods (Fig. 3) were consistent with findings in the gall bladder described above. The calculated values of filtration coefficient indicated increasing resistance to water flow with the rise in luminal hypertonicity (Table II). However, findings in the jejunum of the 2-wk-old rats were contrary to those in other segments indicating a linear rather than a nonlinear relationship between rate of influx of water and rise in hypertonicity of the luminal fluids (Fig. 3). The calculated values of filtration coefficient of water indicated a slight decrease rather than an increase in resistance to water flow from serum-to-lumen, with a rise in luminal hypertonicity (Table II). Inasmuch as during perfusion of the solutions with the higher osmolalities (500 and $700 \mathrm{mosmol} / \mathrm{kg}$ ) the water content of the segments had approached a minimum, around $77 \%$ (Table I), it may be assumed that the epithelial intercellular spaces were collapsed in the perfused segments of all rats at the three age periods. It is possible that the differences in the relationships between rates of water influx and resistance to water flow, in response to luminal hypertonicity between segments of the 2-, 3-, and 7 -wk-old rats, were due to differences in response of the epithelial tight junctions or intercellular spaces of the segments, to luminal hypertonicity. It is also possible that in the perfused segments, water could have been transported through epithelial cells and membranes, especially when perfusion fluid osmolality was high (500 and $700 \mathrm{mosmol} / \mathrm{kg}$ ). In the gall bladder, osmotic water flow into the lumen has been proposed to proceed mainly through the epithelial cells and cell membranes, rather than through intercellular spaces and tight junctions $(23,25)$. In the present study of young growing rats and in previous studies of adult rats $(5,26)$, mannitol (with an estimated molecular radius of $4.0 \AA$ ) and phenol red did not cross the mucosal membrane of either jejunum or ileum in significant amounts (Table I), suggesting that the permeability of the mucosal membrane to mannitol and phenol red was not markedly different in the intestine of the 2-, 3 -, and 7-wk-old rats, and the equivalent "pore" radius of the intestinal epithelium (cell membrane and shunt pathways) were probably not greater than $4 \AA$ reported for adult rats $(27-30)$.

The difference in the resistance to osmotic water movement between segments of 2-, 3-, and 7-wk-old rats could have been related to changes in mucosal membrane structure and composition during maturation. The biochemical composition of the brush border membrane of the intestine has been shown to alter during development in rabbits and rats $(31,32)$. Because at each level of osmolality the transport of water in the segments of the 3-wk-old rats was intermediate between those of the 2- and 7-wk-old rats, it would appear that such a maturational phenomenon is a rather slow process and occurs sometime after the weaning age in rats.

Similarly, in reports by other investigators (33-37) in the present study, secretion of water and electrolytes was found to be greater in the jejunum than in the ileum. This difference in permeability between the jejunum and ileum has been postulated to be due to the existence of much larger pores in the mucosal membrane of the jejunum than in the ileum $(7,35,36)$.

In the jejunal segments, the influx of water was accompanied by net solute influx of which sodium and chloride formed the major components (Figs. 1 and 2). The proportional influx of water and electrolyte suggested solute drag, bulk water flow in response to hypertonicity of the luminal fluids $(19,38)$. In contrast to the jejunal segments, in the ileal segments the influx of water was not associated with a proportional influx of solutes, in fact chloride was transported out of the lumen in the ileal segments of the 3-and 7-wk-old rats regardless of the hypertonicity of the luminal fluids. The findings in the 7-wk-old rats were consistent with those reported in the small intestine of the adult human, where the apparent reflection coefficients for $\mathrm{Na}$ and urea were approximately 0.5 in the jejunum and close to unity in the ileum (7). 
The finding that chloride entered the lumen of the jejunum and ileum in the 2-wk-old rats when luminal osmolality was high suggested that during early infancy the small intestine is unable to conserve chlordie from hypertonic solutions as may occur during episodes of osmotic diarrhea. The ability to conserve chloride appears to develop by the 3rd wk of life in rats. The conservation of chloride appears to be more efficient than that for sodium, at least at the concentration used in the present studies. This probably serves as a protective mechanism.

In the 2-wk-old rats, body weight (water content) was about $14 \%$ of the corresponding values in the 7 -wkold rats, yet actual amount of water lost during perfusion with each of the hypertonic solutions was about the same in the two groups of rats (Table I). Thus, during osmotic diarrhea, the relatively larger losses of water, sodium, and chloride into the intestine in the infant than in the older rats would predispose them to develop dehydration and electrolyte imbalance more readily than adults.

\section{REFERENCES}

1. Miller, S. A., and D. M. Czajka. 1967. The influence of dietary osmolarity on survival in the neonatal rat. Biol. Neonate. 11: 197-203.

2. Younoszai, M. K., and A. Lynch. 1974. In vivo intestinal absorption of hexose in growth-retarded suckling rat pups. J. Nutr. 104: 671-677.

3. Younoszai, M. K., and A. Lynch. 1975. In vivo D-glucose absorption in the developing rat small intestine. Pediatr. Res. 9: 130-133.

4. Schedl, H. P., and J. A. Clifton. 1961. Small intestinal absorption of steroids. Gastroenterology. 41: 491-499.

5. Miller, D. L., and H. P. Schedl. 1972. Nonabsorbed indicators: a comparison of Phenol Red and Inulin- ${ }^{14} \mathrm{C}$ and effects of perfusion technique. Gastroenterology. 62: 48-55.

6. Huntsberger, D. V., and P. E. Leaverton. 1970. Statistical Inference in the Biomedical Sciences. Allyn \& Bacon Inc., Boston. 127.

7. Fordtran, J. S., F. C. Rector, Jr., M. F. Ewton, N. Soter, and J. Kinney. 1965. Permeability characteristics of the human small intestine. J. Clin. Invest. 44: 1935-1944.

8. Heggeness, F. W., D. Bindschadler, J. Chadwick, P. Conklin, S. Hulnick, and M. Oaks. 1961. Weight gains of overnourished and undernourished preweanling rats. J. Nutr. 75: 39-44.

9. DiBona, D. R., L. C. Chen, and G. W. G. Sharp. 1974. A study of intercellular spaces in the rabbit jejunum during acute volume expansion and after treatment with cholera toxin. J. Clin. Invest. 53: 1300-1307.

10. Okada, Y., A. Irimajiri, and A. Inouye. 1977. Electrical properties and active solute transport in rat small intestine. II. Conductive properties of transepithelial routes. J. Membr. Biol. 31: 221-232.

11. Frömter, E., and J. Diamond. 1972. Route of passive ion permeation in epithelia. Nat. New Biol. 235: 9-13.

12. Munck, B. G., and S. G. Schultz. 1974. Properties of the passive conductance pathway across in vitro rat jejunum. J. Membr. Biol. 16: 163-174.
13. Frizzell, R. A., and S. G. Schultz. 1972. Ionic conductances of extracellular shunt pathway in rabbit ileum: Influence of shunt on transmural sodium transport and electrical potential differences. J. Gen. Physiol. 59: 318-346.

14. Frömter, E. 1972. The route of passive ion movement through the epithelium of necturus gallbladder.J. Membr. Biol. 8: 259-301.

15. Ussing, H. H., D. Erlij, and U. Lassen. 1974. Transport pathways in biological membranes. Annu. Rev. Physiol. 36: $17-49$.

16. Huss, R. E., and D. J. Marsh. 1975. A model of $\mathrm{NaCl}$ and water flow through paracellular pathways of renal proximal tubules. J. Membr. Biol. 23: 305-347.

17. Tai, Y. H., J. F. Desjeux, G. Danisi, and P. F. Curran. 1977. $\mathrm{Na}$ and $\mathrm{Cl}$ transport and short-circuit current in rabbit ileum. J. Membr. Biol. 31: 189-208.

18. Sackin, H., and E. L. Boulpaep. 1975. Model for coupling of salt and water transport: Proximal tubular reabsorption in necturus kidney. J. Gen. Physiol. 66: 671-733.

19. Schultz, S. G., R. A. Frizzell, and H. N. Nellans. 1974. Ion transport by mammalian small intestine. Annu. Rev. Physiol. 36: 51-91.

20. Loeschke, K., C. J. Bentzel, and T. Z. Csáky. 1970. Asymmetry of osmotic flow in frog intestine: functional and structural correlation. Am. J. Physiol. 218: 1723-1731.

21. Smulders, A. P., J. M. Tormey, and E. M. Wright. 1972. The effect of osmotically induced water flows on the permeability and ultrastructure of the rabbit gallbladder. J. Membr. Biol. 7: 164-197.

22. Tomasini, J. T., and W. O. Dobbins. 1970. Intestinal mucosal morphology during water and electrolyte absorption: A light and electron microscopic study. Am. J. Dig. Dis. 15: 226-238.

23. Wright, E. M., A. P. Smulders, and J. M. Tormey. 1972. The role of the lateral intercellular spaces and solute polarization effects in the passive flow of water across the rabbit gallbladder. J. Membr. Biol. 7: 198-219.

24. Diamond, J. M. 1966. Non-linear osmosis. J. Physiol. (Lond.). 183: 58-82.

25. Van Os, C. H., and J. F. G. Slegers. 1973. Path of osmotic water flow through rabbit gall bladder epithelium. Biochim. Biophys. Acta. 291: 197-207.

26. Miller, D. L., and H. P. Schedl. 1970. Total recovery studies of nonabsorbable indicators in the rat small intestine. Gastroenterology. 58: 40-46.

27. Höber, R., and J. Höber. 1937. Experiments on the absorption of organic solutes in the small intestine of rats. J. Cell. Comp. Physiol. 10: 401-422.

28. Lindemann, B., and A. K. Solomon. 1962. Permeability of luminal surface of intestinal mucosal cells. J. Gen. Physiol. 45: 801-810.

29. Solomon, A. K. 1960. Measurement of the Equivalent Pore Radius in Cell Membranes. In Membrane Transport and Metabolism. A. Lkeinzeller and A. Kotyk, editors. Academic Press, Inc., New York. 94.

30. Cassidy, M. M., and C. S. Tidball. 1967. Osmotic water flow and solute transfer and solute transfer across the small intestine. Biophys. J. 7: 52A. (Abstr.)

31. Leitch, G. J. 1971. Regional variations in the composition of purified brush borders isolated from infant and adult rabbit small intestine. Arch. Int. Physiol. Biochim. 79: 279-286.

32. Raul, F., P. Simon, M. Kedinger, and K. Haffen. 1977. Intestinal enzyme activities in isolated villus and crypt cells during postnatal development of the rat. Cell Tissue Res. 176: 167-178.

33. Loehry, C. A., A. T. R. Axon, P. J. Hilton, R. C. Hider, 
and B. Creamer. 1970. Permeability of the small intestine to substances of different molecular weight. Gut. 11: 466-470.

34. Chadwick, V. S., S. F. Phillips, and A. F. Hofmann. 1977. Measurements of intestinal permeability using low molecular weight polyethylene glycols (PEG 400). II. Application to normal and abnormal permeability states in man and animals. Gastroenterology. 73: 247-251.

35. Powell, D. W., and S. J. Malawer. 1968. Relationship between water and solute transport from isomotic solutions by rat intestine in vivo. Am. J. Physiol. 215: 49-55.
36. Ross, A., A. W. Rubin, and J. J. Deren. 1972. Differential permeability of the proximal and distal rabbit small bowel. J. Clin. Invest. 51: 2414-2419.

37. Kinsey, M. D., G. J. Dammin, S. B. Formal, and R. A. Giannella. 1976. The role of altered intestinal permeability in the pathogenesis of Salmonella diarrhea in the rhesus monkey. Gastroenterology. 71: 429-434.

38. Lifson, N., L. M. Gruman, and D. G. LeVitt. 1968. Diffusive-convective models for intestinal absorption of $\mathrm{D}_{2}$ O. Am. J. Physiol. 215: 444-454. 